\title{
The electrical conductive behaviours of polymer-based three-phase composites prepared by spatial confining forced network assembly
}

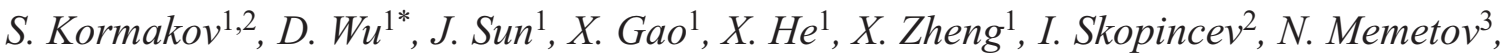 \\ A. Tkachev ${ }^{4}, Z$. Zhi ${ }^{5}$ \\ ${ }^{1}$ College of Mechanical and Electrical Engineering, Beijing University of Chemical Technology, Beijing, China \\ ${ }^{2}$ Department of Processes and Devices in Chemical Technology, Moscow Polytechnic University, Moscow, Russia \\ ${ }^{3}$ Department of Nanotechnology Engineering, Tambov State Technical University, Tambov, Russia. \\ ${ }^{4}$ Department of Technology and Methods of Nanoproducts Manufacturing, Tambov State Technical University, Tambov, \\ Russia. \\ ${ }^{5}$ Department of Materials Science and Chemical Engineering, Stony Brook University, NY, USA
}

Received 9 January 2019; accepted in revised form 16 March 2019

\begin{abstract}
Spatial Confining Forced Network Assembly (SCFNA) method is an effective method for the enhancement of electrical conductivity. In the current paper, a composite material consisting of polydimexilsiloxane (PDMS) and short carbon fiber ( $\mathrm{SCF}$ ) was modified by adding graphene nanoplateletes $(\mathrm{Gr})$ at a concentration of $1 \sim 4 \mathrm{wt} \%$ into the composite system. The electrical properties of the obtained samples were compared with those prepared by compression molding to evaluate the effectiveness of SCFNA. The results showed that the addition of graphene increased the electrical conductivity of the composites by more than 4 orders of magnitude. Meanwhile, a polymer-based three-phase composite with the highest electrical conductivity of $287 \mathrm{~S} / \mathrm{m}$ was obtained utilizing the SCFNA method in the present work.
\end{abstract}

Keywords: polymer composites, spatial confining forced network assembly, graphene, short carbon fiber

\section{Introduction}

Polymer materials are widely used in various industries due to their unique properties, such as low density, high processability and modifiability, strong chemical resistance, etc. [1-7] However, most largevolume types of polymers belong to the class of insulators, due to their high-volume resistivity, and their specific electrical resistance range from $10^{11}$ to $10^{14} \Omega \cdot \mathrm{m}$ [8]. To increase the conductivity of polymer materials, introducing conductive filler into the polymer matrix is commonly used [9]. Currently, various types of fillers haven been attempted to improve these characteristics of conductive polymer composites (CPCs). The most popular fillers are carbon-based materials, i.e., carbon fibers [10-12], carbon black [13-15], carbon nanotubes (CNT) [16-18] and graphene $[19,20]$. These materials have a number of distinctive characteristics, such as good processability, low cost, low density (especially in comparison to metal fillers), high rates of mechanical, electrical and thermal properties, stability, and comparative unpretentiousness to storage conditions.

A significant increase of conductive characteristics of CPCs is provided by organizing the conductive networks (clusters) consisting of filler particles in the polymer matrix. The structure of such networks is usually characterized by the size, the geometric shape, and concentration of the filler. A high characteristics 
of these structures would be observed if the fillers have a large contact surface and aspect ratio, see examples in the previous studies, carbon fiber [10,21], CNTs $[17,22]$ and graphene $[19,23]$. For example, in work [22] a wide review of works aimed at studying the relationship between the geometric shape of the filler and the structure of the polymer composites was presented. The authors show that, depending on the geometric shape of the filler, the volume of filler fraction in relation to the polymer is an essential factor for the structure of the polymer composite. The large filler surface leads to an increase of the internal energy of the matrix-filler system by increasing the surface energy of the two phases. This value contributes to the activation of the mechanism of coagulation of particles and the formation of filler clusters. It can be concluded that nanostructures with a high aspect ratio make it possible to form conducting clusters much more efficiently than fillers with a spherical shape (aspect ratio $A=1$ ). The most effective way to improve the electrical conductivity behavior of CPCs is increasing the concentration of the filler, which leads to a denser arrangement of filler particles in the matrix and simplifies the mechanism of conductivity between them. However, in a certain case, the higher concentration would lead to a critical decrease in the physical and mechanical properties of composite [9, 23].

Recently the research studies demonstrated the emergence of new effective methods for organizing filler networks to improve the conductive properties of CPCs. For example, the method of adding conductive filler to the system of two mutually immiscible matrices $[24,25]$ and the method of polymerization in situ $[26,27]$ were widely implemented to increase the properties of electrical conductivity. However, the conducting characteristics of CPCs obtained in the considered works are still significantly lower than the corresponding values of filler. This phenomenon can be explained by the fact that the layer of the polymer matrix between the filler particles, which is invariably included in the composite structure, has a significant effect on the resistance of the produced materials. Hence, it is concluded that the preparation of CPCs should minimize the distance between the conductive fillers to achieve high conductive characteristics.

It is well-known that the use of nanoparticles for the preparation of composite materials based on the polymer matrix can significantly reduce the percolation threshold of the materials and increase their conductive characteristics [28-30]. This result primarily comes from the high aspect ratio of nanofillers which eases the direct physical contact of particles, leading to expeditious formation of a lattice-like structure. At the same time, the combination of micro and nanoparticles ensures a combined effect in the preparation of polymer composites [31-34]. This effect of fillers combination allows increasing the conductive properties of material that cannot be obtained by using these fillers separately. This phenomenon could be explained regarding the fact that the smaller nanoparticles are able to occupy a position in the volume of the matrix, where micro-sized fibers are no longer able to penetrate. Thus, the presence of nanoparticles can significantly reduce the resistance of polymer layers between the micro-sized fillers. A number of recent works aimed at understanding the influences of the addition of conductive nanoparticles on polymer/carbon filler mixtures [34, 40, 41]. Kandare et al. [34] found that the addition of $1 \mathrm{vol} \%$ graphene nanoplatelets allowed an increase in the volume electroconductivity of carbon/epoxy composite by $55 \%$. It was noted that the inclusion of silver nanoparticles/nanowires at $0.05 \mathrm{vol} \%$ achieved a similar level of increasing in the through-thickness electrical conductivity to the value of $\sim 400 \Omega \cdot \mathrm{cm}$. Guo et al. [40] achieved an increase in the out-of-plane electrical conductivity of the epoxy/graphite fiber composite material from by $144 \%$ to $55 \Omega \cdot \mathrm{cm}$ due to the introduction of $2 \mathrm{wt} \%$ single-walled carbon nanotubes. However, the high cost of the raw materials and the complexity of their processing still make it difficult to utilize these types of fillers in a high volume manufacturing process.

In recent works [35-38], the SCFNA method was described on the example of thin films. The influence of this method on the electrical [36] and thermal [38] conductivity of thin composites based on PDMS matrix was studied. The efficiency of this approach for the use of thermoplastic matrices on the example of carbon fiber and polypropylene was also demonstrated in [35]. For the theoretical study of SCFNA method, a mathematical model was created [37], and the compression ratio was used to numerically determine the effect of the method and predict electrical behaviour of CPCs. This technique ensures an effective compaction of filler particles in the polymer matrix of CPC by a two-stage pressing and thereby improves the conductive properties of the material 
without increasing the filler concentration. This technique can significantly improve the conductivity of the CPC, both on the basis of thermoplastic and thermosetting matrix, mixed with high aspect ratio filler. The main idea of the SCFNA method is to provide additional mechanical action on the filler particles in the process of composite production. The application of an external force would initiate the forced assembly of the filler particles into the conductive networks to confine the space of the pressing mold. This effect allows achieving a more compacted structure of these conductive clusters. As shown in Figure 1, the SCFNA process mainly involves three steps. Firstly, a homogeneous dispersion mixture of conductive fillers and polymer was obtained by melt compounding or solution mixing, depending on the selection of matrix material. The second stage consists a pressing process on the resulting homogeneous dispersion mixture to initialize the self-assembly mechanism of filler particles into conductive networks. In the final stage, further compression of the samples will produce the network structure with the thickness $(h)$ less than the diameter of the conductive cluster $\left(d_{\mathrm{m}}\right)$. This stage produced the final composite with a compacted conductive network. It is important to note that the object of the forced assembly was the structure of the fillers that have passed the stage of self-assembly, not homogeneously distributed filler particles. The mechanism of forced-assembly can be described as follows. The process of pressing samples in a confining space, characterized by the thickness of the sample less that diameter of the conductive cluster of the filler, is accompanied by a direct impact of the pressing force on the filler particles and shifts the balance of forces established as a result of the process of self-assembly.
Under the external force, the particles begin a mutual interplay with each other until a new stable status is established, which is due to the balance between the external force and the repulsion forces. This balanced state can be fixed by curing of the polymer matrix. Thus, the clusters formed by the process of self-assembly can be converted into a force-assembled compact network with the increased conductivity characteristics. Wu et al. [36] proposed that SCFNA method allows obtaining PDMS/carbon fiber binary composites with a low percolation threshold of $0.15 \mathrm{wt} \%$. At the same time, the exclusion volume effect provided by the use of bolting cloth was studied. The analysis of dispersion and location of the carbon fibers in PDMS, the average gap between adjacent carbon fibers in the network and the micrographs of the SCF conductive network on the composite sheets surface were used to verify the effectiveness of the forced assembly. High electrically conductive SCF based composites with PP matrix were also prepared by SCFNA method [35]. A morphology evolution model of SCFNA process was proposed. It was be noted that forced assembly conductive network may be formed by compressing of samples to a thickness less than the average diameter of the self-assembly clusters. The study of the obtained samples revealed an increase in electrical conductivity up to 4 orders of magnitude higher than that of composites prepared by the traditional compounding technology. With the increase of the compression ratio, after modifying the percolation threshold by SCFNA method, the electrical conductivity of the samples could increase several times due to the increase of forced assembly degree. At the same time, at the first stage of mixing, if the smaller particles (for example, graphene) are

a)

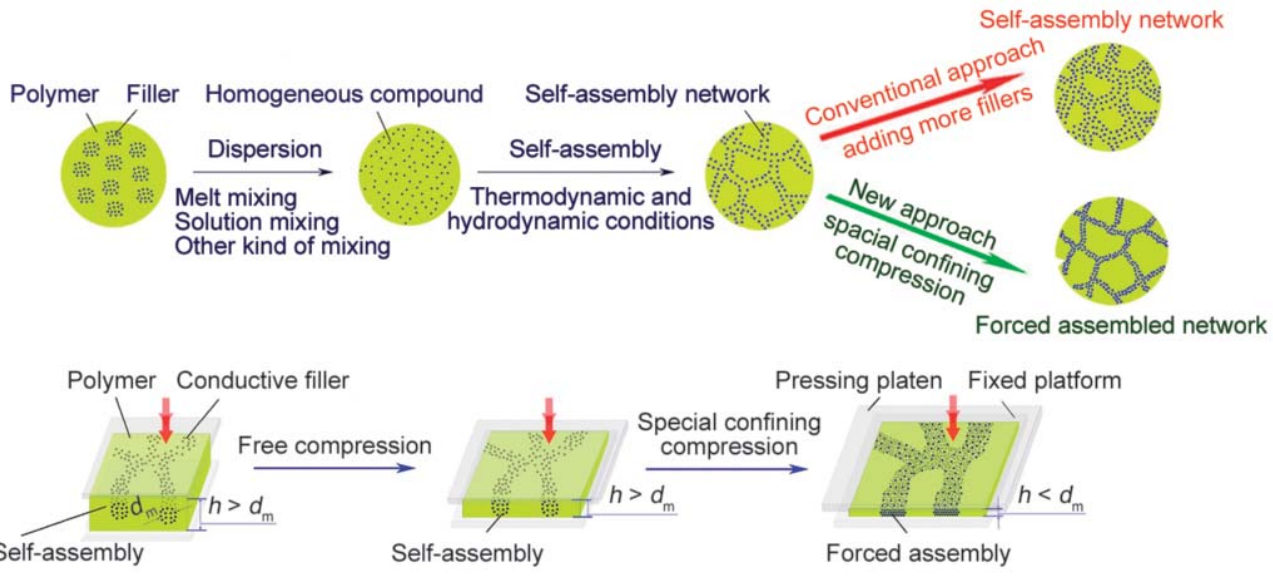

Figure 1. The sketch of the SCFNA method [35]: a) the technological pathway of SCFNA and the conventional compounding approach, b) the free compression and the spatial confining compression. 
also added into compounding, it is reasonable that the cumulative effect of the two fillers together with the influence of the applied external force of the SCFNA method will significantly increase the final characteristics of the obtained material.

\section{Experiments}

\subsection{Materials}

A number of experiments were conducted in the current study. Short carbon fibers (SCF) Toray T300 with a diameter of $5-10$ microns, a length of $1-5 \mathrm{~mm}$, carbon content $93 \%$ and a density of $1.76 \mathrm{~g} / \mathrm{cm}^{3}$ (TORAY, Japan) and the water paste of graphene 'Taunit-GM' (NanoTechCenter LTD, Russia) with number of layers $-3-5$, thickness of platelets $-1-$ $3 \mathrm{~nm}$, size in the plane $2-10 \mu \mathrm{m}$, containing of sulfur $\leq 0.7 \mathrm{wt} \%$, oxygen content relative to carbon, 9$13 \mathrm{wt} \%$, were used as the fillers. Polydimethylsiloxane (PDMS) matrix Sylgard 184 Silicone Elastomer (Dow Corning Corp, USA) was used as the polymer matrix, which is a two-component elastomer consisting of a base resin (component $\mathrm{A}$ ) and a curing agent (component B). During the preparation, these components were mixed in a ratio of 10:1. The viscosity of PDMS is $3900 \mathrm{mPa} \cdot \mathrm{s}$, density in the cured state is $1.030 \mathrm{~g} / \mathrm{cm} \S$, time of curing is $10 \mathrm{~min}$ with temperature $150^{\circ} \mathrm{C}$.

\subsection{Equipment}

A conical twin-screw mixer HAAKE MiniLab (Thermo Fisher Scientific, USA) was used to ensure the preparation of the pre-mix corresponding to the first stage of the SCFNA method. A custom made laboratory press was used for the process of pressing samples $[35,36]$. This device provides a pressing force up to $50 \mathrm{kN}$ with regulation of pressing speed from 0.005 to $0.5 \mathrm{~mm} / \mathrm{s}$, the servo motor is controlled by a PLC system and the position of the up plate was guaranteed accuracy of $\pm 3 \mu \mathrm{m}$. The design of the mold allows pressing samples of different thickness and diameter of $50 \mathrm{~mm}$ in the confined space.

Hitachi S-4700 (Hitachi High-Technologies Corporation, Japan) Scanning Electron Microscope (SEM) at an accelerating voltage $20 \mathrm{kV}$ was used to study the distribution of the filler in the body of the samples. The direct current (DC) electrical conductivities of the composites over $10^{-6} \mathrm{~S} / \mathrm{m}$ were measured by a ZC-90D resistivity meter from Shanghai Taiou Electronics (China).

\subsection{Preparation}

The graphene paste was dissolved in ethanol by mixing for 15 minutes at a speed of $20 \mathrm{rpm}$ by open mixer. After that, carbon fiber was pre-dried under vacuum at a temperature of $100^{\circ} \mathrm{C}$ for 1 hour and then was added to the mixture with a concentration of 1 to $4 \%$ by weight. In the next step, the obtained mixture of SCF and graphene was mixed with the component $\mathrm{A}$ in a two-screw mixer HAAKE Mini$\mathrm{Lab}$ at a temperature of $80{ }^{\circ} \mathrm{C}$ and a screw speed of $50 \mathrm{rpm}$ for 15 mins. After that, the mixture was placed in a vacuum oven with a temperature of $60^{\circ} \mathrm{C}$ for 8 hours to remove the residual ethanol and air bubbles which is formed in the process of mixing. In the following step, a curing agent (component B) was added to the mixture and the samples were pressed. The scheme of CPCs preparation is shown in Figure 2. To study the effect of the SCFNA method, the obtained mixture with the curing agent was subjected to a two-stage compression. The first stage of the process was carried out for 60 seconds with a $2 \mathrm{~mm}$ thick sample holder to ensure the implementation of self-assembly of the filler in the conductive network without pressing force. During this time, the material was in a viscous state. At the second stage, the samples were further pressed to thicknesses of 150, 250, 350 and 450 microns with a pressing force of $50 \mathrm{kN}$. After that, the sample was kept under pressure for 10 minutes. The curing of the material was provided by the fact that the two-stage pressing process was carried out at a mold temperature of $150^{\circ} \mathrm{C}$. To distinguish the effect of self-assembly network and forced-assembly network on electrical conductivities of the composites, the samples with a thickness of

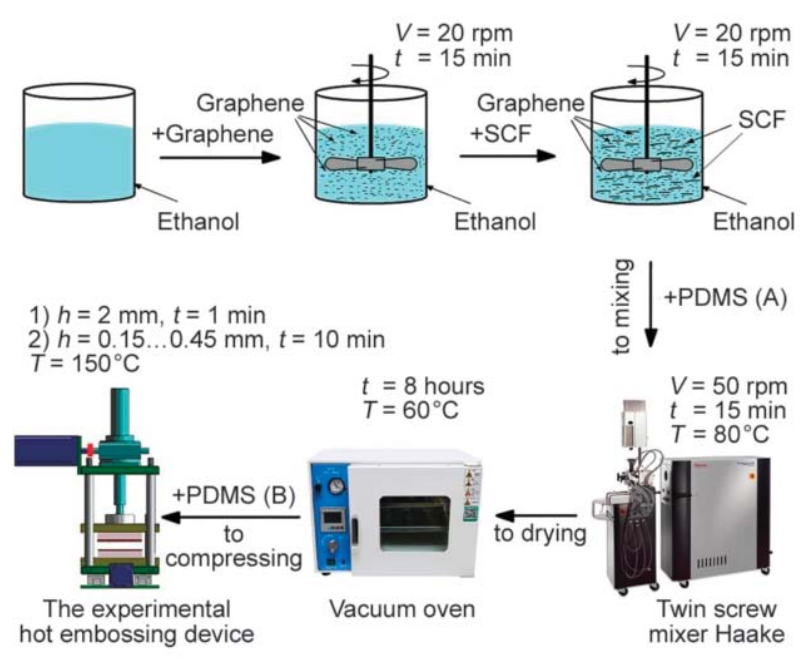

Figure 2. Schematic illustrations of the preparation process of SCFNA samples. 
$2.0 \mathrm{~mm}$ after the first stage of compression were prepared, which is denoted as the CPCs by a conventional compounding method. In order to verify the reproducibility, 5 samples were obtained and analyzed for each concentration of the mixtures. As a result of the work, the average results of the measured conductivity are considered, the maximum measurement error does not exceed $10 \%$.

\section{Results and discussions}

As a result, a series of samples with a concentration of SCF from 1 to $4 \mathrm{wt} \%$, each containing from 0 to $4 \mathrm{wt} \%$ of graphene was obtained. The results of measurements of the electrical conductivity of the samples are listed in Table 1. Figure 3 shows the electrical conductivity of samples without graphene, samples with thicknesses from 150 to 450 microns and samples made by the traditional compounding method. As shown in Figure 3, the electrical conductivity of the material increases with the decreasing thickness, this can be explained by the compaction of conductive filler networks as a result of external force [36].

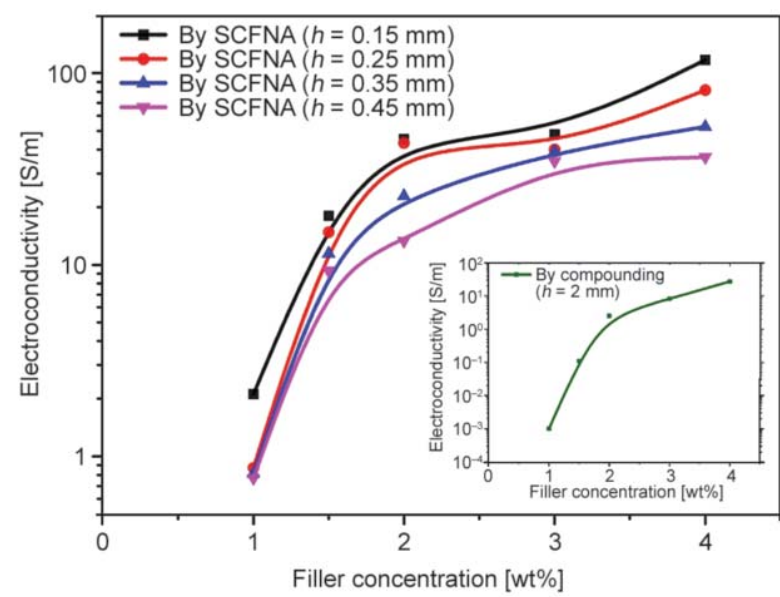

Figure 3. Comparison of electrical conductivities of PDMS/ SCF composites prepared by SCFNA and compounding method.

While, the results in Figure 4 indicate that the current method is practical rather than effective when graphene nanoplatelets are using without SCF. A significant change in the electrical conductivity with a decreasing in the thickness is observed when comparing the traditional compounding method and the

Table 1. Electrical conductivities of the PDMS/SCF+Gr composite by SCFNA and compounding methods.

\begin{tabular}{|c|c|c|c|c|c|c|c|}
\hline \multirow{2}{*}{$\begin{array}{c}\text { Graphene content } \\
{[\mathbf{w t} \%]}\end{array}$} & \multirow{2}{*}{$\begin{array}{l}\text { Thickness } \\
{[\mathrm{mm}]}\end{array}$} & \multicolumn{6}{|c|}{$\begin{array}{l}\text { The electrical conductivity of the samples } \\
{\left[\begin{array}{l}{[\mathrm{S} / \mathrm{m}]} \\
\end{array}\right.}\end{array}$} \\
\hline & & $\mathrm{SCF}=0 \%$ & $\mathrm{SCF}=1 \%$ & $\mathrm{SCF}=1.5 \%$ & SCF $=2 \%$ & $\mathrm{SCF}=3 \%$ & $\mathrm{SCF}=4 \%$ \\
\hline \multirow{5}{*}{$\mathrm{Gr}=0 \%$} & 0.15 & \multirow{5}{*}{$\mathrm{n} / \mathrm{a}$} & 2.11 & 18.00 & 45.33 & 48.00 & 117.33 \\
\hline & 0.25 & & 0.87 & 14.80 & 43.20 & 40.00 & 81.60 \\
\hline & 0.35 & & 0.81 & 11.43 & 22.86 & 38.86 & 52.57 \\
\hline & 0.45 & & 0.77 & 9.33 & 13.33 & 34.67 & 36.44 \\
\hline & 2 & & $0.01 \cdot 10^{-1}$ & 0.11 & 2.50 & 8.11 & 27.00 \\
\hline \multirow{5}{*}{$\mathrm{Gr}=1 \%$} & 0.15 & $1.27 \cdot 10^{-11}$ & 2.67 & 21.33 & 94.40 & 162.67 & 232.00 \\
\hline & 0.25 & $1.53 \cdot 10^{-12}$ & 0.96 & 19.20 & 44.57 & 152.00 & 224.00 \\
\hline & 0.35 & $8.49 \cdot 10^{-13}$ & 0.86 & 17.14 & 40.00 & 148.57 & 218.74 \\
\hline & 0.45 & $9.17 \cdot 10^{-13}$ & 0.82 & 12.44 & 24.89 & 141.67 & 183.91 \\
\hline & 2 & $9.10 \cdot 10^{-13}$ & $0.06 \cdot 10^{-1}$ & 3.12 & 22.19 & 48.64 & 78.92 \\
\hline \multirow{5}{*}{$\mathrm{Gr}=2 \%$} & 0.15 & $8.22 \cdot 10^{-11}$ & 5.33 & 24.80 & 115.20 & 167.73 & 258.67 \\
\hline & 0.25 & $1.47 \cdot 10^{-11}$ & 4.41 & 22.81 & 68.34 & 156.84 & 240.00 \\
\hline & 0.35 & $5.32 \cdot 10^{-12}$ & 2.29 & 19.43 & 62.63 & 152.86 & 231.18 \\
\hline & 0.45 & $5.09 \cdot 10^{-12}$ & 1.78 & 17.78 & 44.89 & 145.33 & 204.80 \\
\hline & 2 & $6.37 \cdot 10^{-13}$ & 0.21 & 7.79 & 36.42 & 63.11 & 91.03 \\
\hline \multirow{5}{*}{$\mathrm{Gr}=3 \%$} & 0.15 & $6.06 \cdot 10^{-6}$ & 6.46 & 31.84 & 122.40 & 171.47 & 273.71 \\
\hline & 0.25 & $9.09 \cdot 10^{-7}$ & 5.94 & 27.20 & 74.00 & 167.84 & 267.52 \\
\hline & 0.35 & $1.82 \cdot 10^{-6}$ & 4.58 & 24.00 & 69.33 & 162.29 & 245.71 \\
\hline & 0.45 & $1.64 \cdot 10^{-6}$ & 3.56 & 23.11 & 62.22 & 147.33 & 225.78 \\
\hline & 2 & $2.86 \cdot 10^{-11}$ & 1.96 & 9.49 & 44.17 & 73.73 & 94.70 \\
\hline \multirow{5}{*}{$\mathrm{Gr}=4 \%$} & 0.15 & 0.70 & 7.20 & 39.67 & 125.20 & 192.00 & 287.19 \\
\hline & 0.25 & 0.53 & 6.19 & 34.41 & 97.61 & 172.00 & 281.03 \\
\hline & 0.35 & 0.36 & 5.11 & 26.86 & 82.67 & 166.79 & 265.31 \\
\hline & 0.45 & 0.24 & 4.08 & 24.79 & 75.78 & 155.33 & 244.21 \\
\hline & 2 & $0.45 \cdot 10^{-1}$ & 2.21 & 11.03 & 51.61 & 77.52 & 118.00 \\
\hline
\end{tabular}




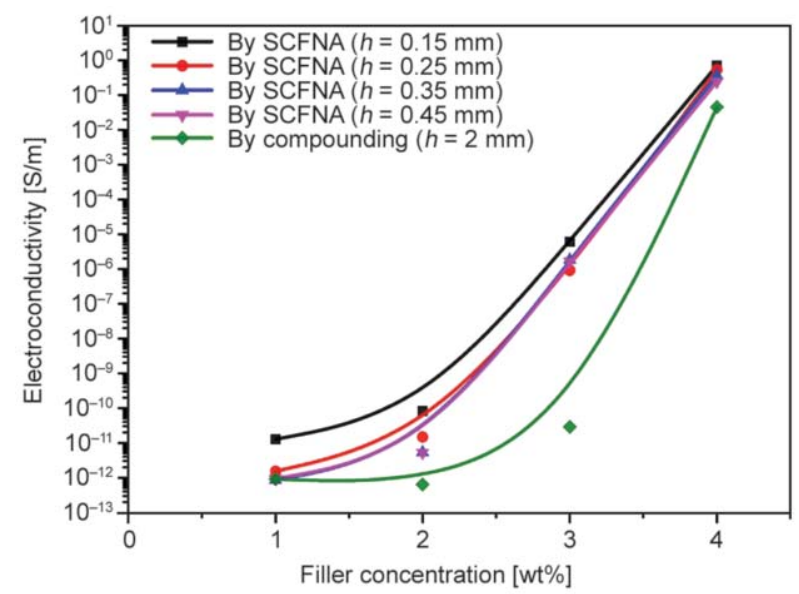

Figure 4. Comparison of electrical conductivities of PDMS/ Gr composites prepared by SCFNA and compounding method.

SCFNA method. With further compression, the characteristics of the material would not show further change. This can be explained by the fact that the average size of the filler, as well as the thickness of the resulting conductive clusters, is too small when it is compared to the change in the thickness of the sample. In this case, it can be concluded that the application of an external force in the sample molding does not significantly affect the location and compactness of nanoscale fillers.

Based on the theoretical foundation of SCFNA method, which is detailed in our earlier studies [3538], it can be assumed that this method can be effective in case of producing samples with a limited thickness $(\sim 0.1-0.5 \mathrm{~mm})$ comparable to the size of agglomerated clusters of filler particles $(\sim 400-600 \mu \mathrm{m})$. However, the possibility of manufacturing such thin samples for nanofillers is currently unavailable. Moreover, it is noted that the final conductivity values of the obtained graphene-based materials are significantly lower than the materials including micro-sized fillers. This can be explained by the fact that the use of nanoparticles requires high-tech processing methods according to their dispersion difficulty in viscous polymer melts [39]. It should be noted that the aim of this work was not to obtain a high distribution of filler nanoparticles, but to introduce them into the network of the conducting cluster which is formed by the carbon fibers. For this purpose, the method of mixing in the melt was applied.

Figure 5 shows the dependence of the conductivity of the obtained samples with SCF concentrations from 1 to $4 \mathrm{wt} \%$ with different thicknesses on the graphene concentration. These results show that the obtained materials with SCF and Gr have a lower resistivity compared to the samples that do not contain graphene. A similar effect is also observed with an increase of the concentration of carbon fiber. The synergistic effect is generated by the coupling of the stable conductive cluster formed by the carbon fiber, and the improved flow of electric charges through the graphene nanoplatelets located in the polymer layer which fills the space between the fibers. Thus, from the comparison between the samples containing $4 \% \mathrm{SCF}$ without graphene, $4 \%$ graphene without $\mathrm{SCF}$ and samples containing $4 \% \mathrm{SCF}+4 \%$ graphene, it is observed that the electrical conductivity can be increased by more than 4 orders of magnitude of those samples prepared by the traditional pressing method. And approximately 86-250 times for samples with different thicknesses were obtained by the SCFNA method with increasing nanoparticle concentrations. The electrical conductivity of the samples with $1 \mathrm{wt} \%$ graphene can be improved by increasing the SCF concentration from 1 to $4 \mathrm{wt} \%$ with more than 13 thousand times for the compounding method. The application of the SCFNA method allows increasing this value by 2.9 times only by reducing the thickness of the sample containing $1 \mathrm{wt} \% \mathrm{Gr}$ and $4 \mathrm{wt} \%$ SCF from 2 to $0.15 \mathrm{~mm}$.

SEM images were taken to study the distribution of the filler in the composite. Figure 6 shows the SEM images of the obtained samples. With increasing scale, it is shown that graphene flakes are located in the polymer layer between carbon fibers. This distribution of nanofiller helps to reduce the resistance of this layer, which significantly affects the characteristics of the obtained composite material.

Figure 7 shows the correlation of the electrical conductivity of the samples on their thickness at different concentrations. It can be noted that a decrease of the thickness and an increase of the concentration lead to improve the conductive behaviour of the obtained CPCs. Thus, the maximum electrical conductivity of CPC $(\sim 287 \mathrm{~S} / \mathrm{m})$ was obtained at a sample thickness of $0.15 \mathrm{~mm}$, containing $4 \mathrm{wt} \%$ SCF and $4 \mathrm{wt} \%$ Gr. This value is $\sim 2.4$ times higher than the $2 \mathrm{~mm}$ thick sample with the same content but produced by the method of compression molding. On the other hand, this sample is comparable in its characteristics to the $0.15 \mathrm{~mm}$ thick sample obtained by the SCFNA method without graphene. In the case where both types of filler are added, the maximum increase of electrical conductivity ( $\sim 45$ times) is observed 

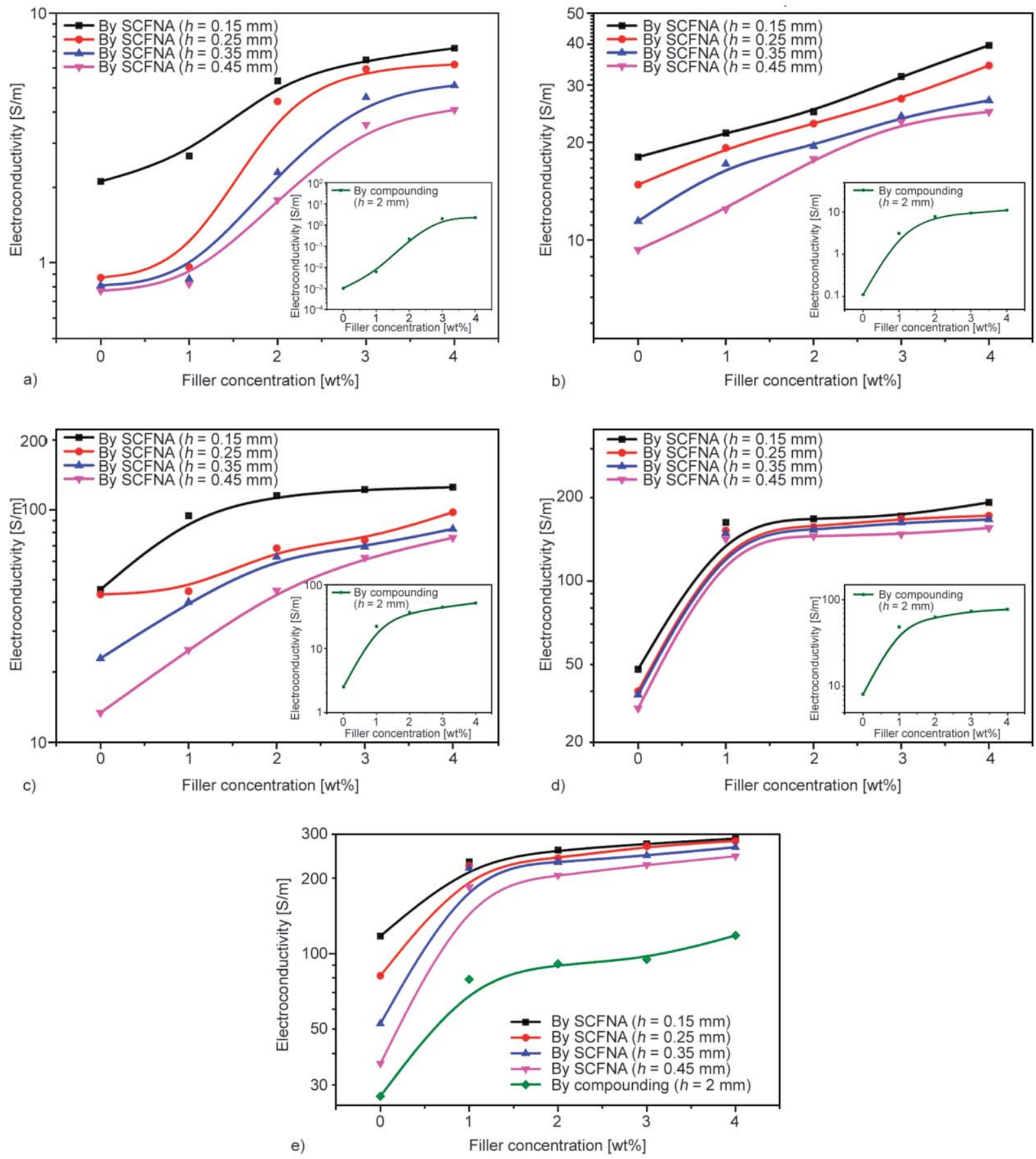

Figure 5. Comparison of electrical conductivities of $\mathrm{PDMS} / \mathrm{SCF}+\mathrm{Gr}$ composites prepared by SCFNA and compounding method: a) samples containing $1 \% \mathrm{SCF}, \mathrm{b}$ ) samples containing $1.5 \% \mathrm{SCF}$, c) samples containing $2 \% \mathrm{SCF}$, d) samples containing $3 \% \mathrm{SCF}$, e) samples containing $4 \% \mathrm{SCF}$.

for samples containing $1 \mathrm{wt} \%$ fiber and $1 \mathrm{wt} \%$ graphene. This note is due to the fact that these concentrations are close to the percolation threshold, which is a sharp drop of the material conductivity during its transition from the insulator to the conductor. The overall cumulative effect, including an increase in the concentration of SCF from 1 to $4 \mathrm{wt} \%$, the concentration of graphene from 0 to $4 \mathrm{wt} \%$ and the using of the SCFNA method proved to improve the electrical conductivity of CPC by more than 287 thousand times. These values demonstrate the high efficiency of combining micro- and nanoscale filler and the application of the SCFNA method.

\section{Conclusions}

A series of samples containing different short carbon fiber and graphene were prepared by the SCFNA method. It was noted that two type fillers in the matrix 


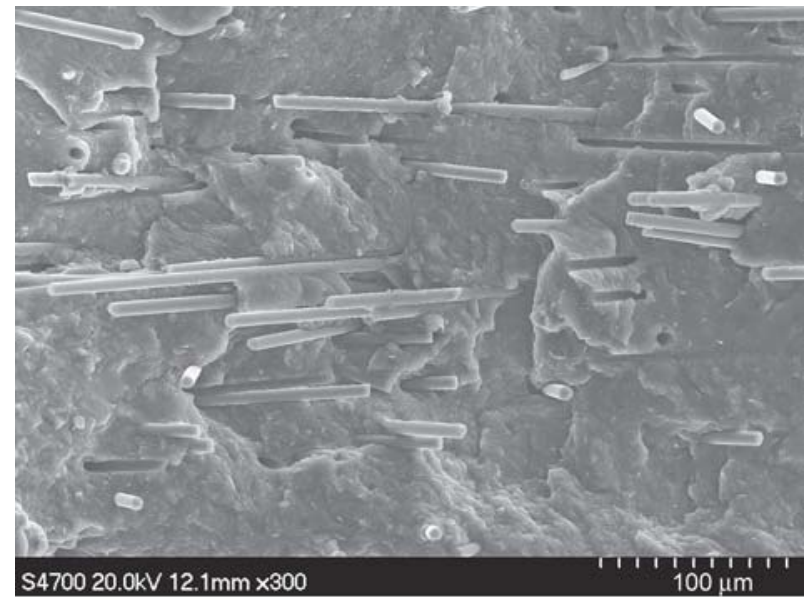

a)

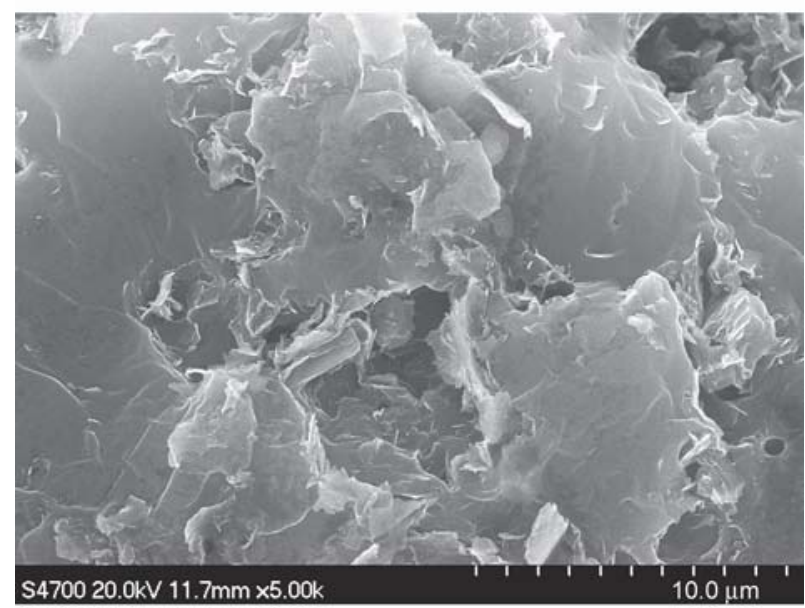

b)

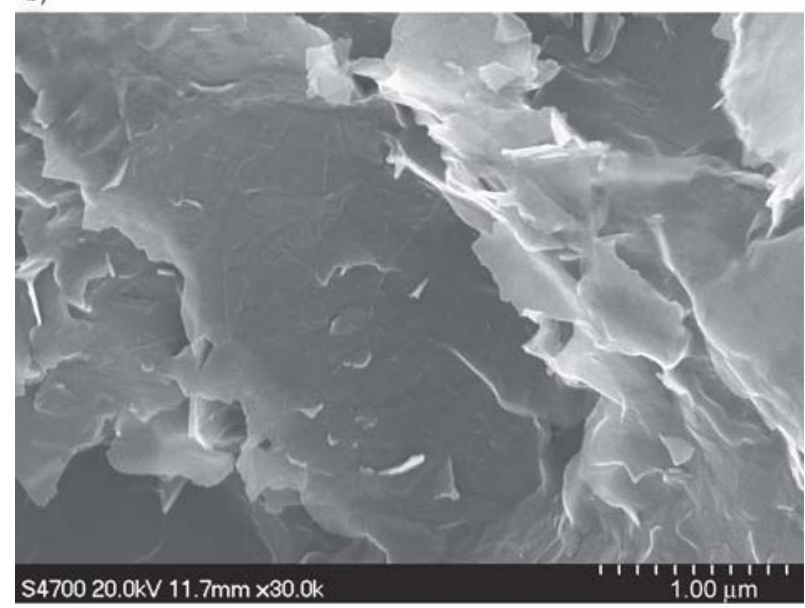

c)

Figure 6. SEM images of the sample with $4 \mathrm{wt} \% \mathrm{SCF}$, $4 \mathrm{wt} \% \mathrm{Gr}$, and thickness of $0.35 \mathrm{~mm}$. Scale bars: a) $100 \mu \mathrm{m}$, b) $10 \mu \mathrm{m}$, c) $1 \mu \mathrm{m}$.

of CPCs leads to a cumulative effect, which significantly increases the conductive behaviour of CPCs. The SCFNA method makes an additional contribution to the reduction of the specific volume electrical resistance of the samples by the external influence self-assembled conductive network of the fillers in the CPCs. This method demonstrates a multiple-step
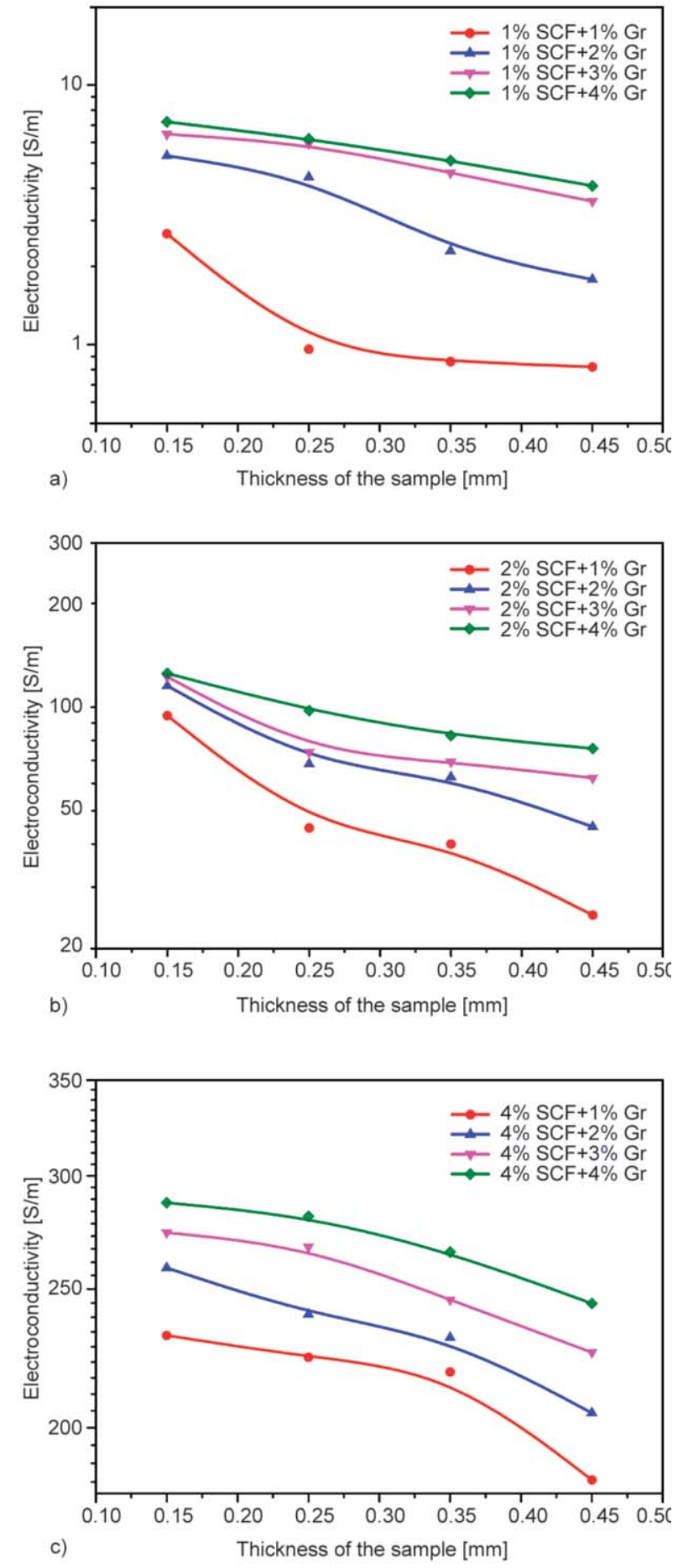

Figure 7. The effect of sample thickness on electrical conductivities of PDMS/SCF+Gr composites: the different contents of graphene with a) $1 \mathrm{wt} \% \mathrm{SCF}$, b) $2 \mathrm{wt} \% \mathrm{SCF}$, and c) $4 \mathrm{wt} \% \mathrm{SCF}$.

processing which increases the electrical conductivity of the composite material, without increasing the filler concentration. The combination of nano- and micro-fillers in the producing of the materials by SCFNA method provides significant enhancement of electrical conductive that unreachable with separate factors. The material obtained in this work can be 
widely used in the manufacture of thin and bulk products and devices that require flexible materials with a high electrical conductivity. First of all, this material can be in demand in the production of flexible strain sensors, PCBs etc. For the applied use of the described material, additional studies of physical and mechanical properties, surface resistance, stability of the resulting material under operating conditions are required.

\section{Acknowledgements}

The authors acknowledge the financial support of National Natural Science Foundation of China (No. 51673020 and No. 51173015).

\section{References}

[1] Kashfipour M., Mehra N., Zhu J.: A review on the role of interface in mechanical, thermal, and electrical properties of polymer composites. Advanced Composites and Hybrid Materials, 1, 415-439 (2018).

https://doi.org/10.1007/s42114-018-0022-9

[2] Hu Z., Shao Q., Huang Y., Yu L., Zhang D., Xu X., Lin J., Liu H., Guo Z.: Light triggered interfacial damage self-healing of poly( $p$-phenylene benzobisoxazole) fiber composites. Nanotechnology, 29, 185602/1-185602/17 (2018).

https://doi.org/10.1088/1361-6528/aab010

[3] Díez-Pascual A. M., Naffakh M., Marco C., GómezFatou M. A., Ellis G. J.: Multiscale fiber-reinforced thermoplastic composites incorporating carbon nanotubes: A review. Current Opinion in Solid State and Materials Science, 18, 62-80 (2014).

https://doi.org/10.1016/j.cossms.2013.06.003

[4] Xie J., Teng L., Yang Z., Zhou C., Liu Y., Yung B., Lee R.: A polyethylenimine-linoleic acid conjugate for antisense oligonucleotide delivery. BioMed Research International, 2013, 710502/1-710502/7 (2013). https://doi.org/10.1155/2013/710502

[5] Tadmor Z., Gogos C. G.: Principles of polymer processing. Wiley, New York (2006).

[6] Lin J., Chen X., Chen C., Hu J., Zhou C., Cai X., Wang W., Zheng C., Zhang P., Cheng J., Guo Z., Liu H.: Durably antibacterial and bacterially antiadhesive cotton fabrics coated by cationic fluorinated polymers. ACS Applied Materials and Interfaces, 10, 6124-6136 (2018). https://doi.org/10.1021/acsami.7b16235

[7] He Y., Yang S., Liu H., Shao Q., Chen Q., Lu C., Jiang Y., Liu C., Guo Z.: Reinforced carbon fiber laminates with oriented carbon nanotube epoxy nanocomposites: Magnetic field assisted alignment and cryogenic temperature mechanical properties. Journal of Colloid and Interface Science, 517, 40-51 (2018) https://doi.org/10.1016/j.jcis.2018.01.087
[8] Grossiord N., Loos J., Regev O., Koning C. E.: Toolbox for dispersing carbon nanotubes into polymers to get conductive nanocomposites. Chemistry of Materials, 18, 1089-1099 (2006). https://doi.org/10.1021/cm051881h

[9] Sengupta R., Bhattacharya M., Bandyopadhyay S., Bhowmick A. K.: A review on the mechanical and electrical properties of graphite and modified graphite reinforced polymer composites. Progress in Polymer Science, 36, 638-670 (2011). https://doi.org/10.1016/j.progpolymsci.2010.11.003

[10] Yu G-C., Wu L-Z., Feng L-J., Yang W.: Thermal and mechanical properties of carbon fiber polymer-matrix composites with a 3D thermal conductive pathway. Composite Structures, 149, 213-219 (2016). https://doi.org/10.1016/j.compstruct.2016.04.010

[11] Tian B., Yang W., Luo L., Wang J., Zhang K., Fan J., Wu J., Xing T.: Synergistic enhancement of thermal conductivity for expanded graphite and carbon fiber in paraffin/EVA form-stable phase change materials. Solar Energy, 127, 48-55 (2016). https://doi.org/10.1016/j.solener.2016.01.011

[12] Sharma M., Gao S., Mäder E., Sharma H., Wei L. Y., Bijwe J.: Carbon fiber surfaces and composite interphases. Composites Science and Technology, 102, 35-50 (2014). https://doi.org/10.1016/j.compscitech.2014.07.005

[13] King J. A., Via M. D., King M. E., Miskioglu I., Bogucki G. R.: Electrical and thermal conductivity and tensile and flexural properties: Comparison of carbon black/ polycarbonate and carbon nanotube/polycarbonate resins. Journal of Applied Polymer Science, 121, 2273-2281 (2011). https://doi.org/10.1002/app.33890

[14] Yin B., Wen Y., Jia H., Wang J., Xu Z., Ding L.: Synergistic effects of hybridization of carbon black and carbon nanotubes on the mechanical properties and thermal conductivity of a rubber blend system. Journal of Polymer Engineering, 37, 785-794 (2017). https://doi.org/10.1515/polyeng-2016-0375

[15] Zhang L., Deng H., Fu Q.: Recent progress on thermal conductive and electrical insulating polymer composites. Composites Communications, 8, 74-82 (2018). https://doi.org/10.1016/j.coco.2017.11.004

[16] El-Brolossy T. A., Ibrahim S. S., Alkhudhayr E. A.: Carbon nanotube functionalization effects on thermal properties of multiwall carbon nanotube/polycarbonate composites. Polymer Composites, 36, 1242-1248 (2015). https://doi.org/10.1002/pc.23028

[17] Zhang K., Yu H-O., Shi Y-D., Chen Y-F., Zeng J-B., Guo J., Wang B., Guo Z., Wang M.: Morphological regulation improved electrical conductivity and electromagnetic interference shielding in poly(L-lactide)/poly (E-caprolactone)/carbon nanotube nanocomposites via constructing stereocomplex crystallites. Journal of Materials Chemistry C, 5, 2807-2817 (2017). https://doi.org/10.1039/C7TC00389G 
[18] Sun J., Zhao Y., Yang Z., Shen J., Cabrera E., Lertola M. J., Yang W., Zhang D., Benatar A., Castro J. M., Wu D., Lee L. J.: Highly stretchable and ultrathin nanopaper composites for epidermal strain sensors. Nanotechnology, 29, 355304/1-355304/11 (2018).

https://doi.org/10.1088/1361-6528/aacc59

[19] Kim H. S., Bae H. S., Yu J., Kim S. Y.: Thermal conductivity of polymer composites with the geometrical characteristics of graphene nanoplatelets. Scientific Reports, 6, 26825/1-26825/9 (2016).

https://doi.org/10.1038/srep26825

[20] Kuilla T., Bhadra S., Yao D., Kim N. H., Bose S., Lee J. H.: Recent advances in graphene based polymer composites. Progress in Polymer Science, 35, 1350-1375 (2010).

https://doi.org/10.1016/j.progpolymsci.2010.07.005

[21] Chung D. D. L.: Comparison of submicron-diameter carbon filaments and conventional carbon fibers as fillers in composite materials. Carbon, 39, 1119-1125 (2001). https://doi.org/10.1016/S0008-6223(00)00314-6

[22] George J., Ishida H.: A review on the very high nanofiller-content nanocomposites: Their preparation methods and properties with high aspect ratio fillers. Progress in Polymer Science, 86, 1-39 (2018).

https://doi.org/10.1016/j.progpolymsci.2018.07.006

[23] Polschikov S., Nedorezova P., Klyamkina A., Kovalchuk A., Aladyshev A., Shchegolikhin A., Shevchenko V., Muradyan V.: Composite materials of graphene nanoplatelets and polypropylene, prepared by in situ polymerization. Journal of Applied Polymer Science, 127, 904-911 (2013).

https://doi.org/10.1002/app.37837

[24] Yoo Y., Lee H., Ha S., Jeon B., Won J., Lee S.: Effect of graphite and carbon fiber contents on the morphology and properties of thermally conductive composites based on polyamide 6 . Polymer International, 63, 151157 (2013). https://doi.org/10.1002/pi.4534

[25] Lan Y., Liu H., Cao X., Zhao S., Dai K., Yan X., Zheng G., Liu C., Shen C., Guo Z.: Electrically conductive thermoplastic polyurethane/polypropylene nanocomposites with selectively distributed graphene. Polymer, 97, 11-19 (2016). https://doi.org/10.1016/j.polymer.2016.05.017

[26] Zhang X., Yan X., He Q., Wei H., Long J., Guo J., Gu H., Yu J., Liu J., Ding D., Sun L., Wei S., Guo Z.: Electrically conductive polypropylene nanocomposites with negative permittivity at low carbon nanotube loading levels. ACS Applied Materials and Interfaces, 7, 6125 6138 (2015).

https://doi.org/10.1021/am5082183

[27] Deng H., Lin L., Ji M., Zhang S., Yang M., Fu Q.: Progress on the morphological control of conductive network in conductive polymer composites and the use as electroactive multifunctional materials. Progress in Polymer Science, 39, 627-655 (2014).

https://doi.org/10.1016/j.progpolymsci.2013.07.007
[28] Paszkiewicz S., Szymczyk A., Sui X. M., Wagner H. D., Linares A., Ezquerra T. A., Rosłaniec Z.: Synergetic effect of single-walled carbon nanotubes (SWCNT) and graphene nanoplatelets (GNP) in electrically conductive PTT-block-PTMO hybrid nanocomposites prepared by in situ polymerization. Composites Science and Technology, 118, 72-77 (2015).

https://doi.org/10.1016/j.compscitech.2015.08.011

[29] Kong J., Tong Y., Sun J., Wei Y., Thitsartarn W., Jayven C. C. Y., Muiruri J. K., Wong S. Y., He C.: Electrically conductive PDMS-grafted CNTs-reinforced silicone elastomer. Composites Science and Technology, 159, 208-215 (2018).

https://doi.org/10.1016/j.compscitech.2018.02.018

[30] Zhu J-M., Zare Y., Rhee K. Y.: Analysis of the roles of interphase, waviness and agglomeration of CNT in the electrical conductivity and tensile modulus of polymer/ CNT nanocomposites by theoretical approaches. Colloids and Surfaces A: Physicochemical and Engineering Aspects, 539, 29-36 (2018).

https://doi.org/10.1016/j.colsurfa.2017.12.001

[31] Wentzel D., Sevostianov I.: Electrical conductivity of unidirectional carbon fiber composites with epoxygraphene matrix. International Journal of Engineering Science, 130, 129-135 (2018).

https://doi.org/10.1016/j.ijengsci.2018.05.012

[32] Hallad S. A., Banapurmath N. R., Hunashyal A. M., Shettar A. S., Ayachit N. H., Mruthunjaya A. K., Lohit R. B., Uttur M.: Experimental investigation for graphene and carbon fibre in polymer-based matrix for structural applications. Journal of Applied Research and Technology, 15, 297-302 (2017).

https://doi.org/10.1016/j.jart.2017.01.014

[33] Cheng X., Yokozeki T., Wu L., Wang H., Zhang J., Koyanagi J., Weng Z., Sun Q.: Electrical conductivity and interlaminar shear strength enhancement of carbon fiber reinforced polymers through synergetic effect between graphene oxide and polyaniline. Composites Part A: Applied Science and Manufacturing, 90, 243-249 (2016).

https://doi.org/10.1016/j.compositesa.2016.07.015

[34] Kandare E., Khatibi A. A., Yoo S., Wang R., Ma J., Olivier P., Gleizes N., Wang C. H.: Improving the through-thickness thermal and electrical conductivity of carbon fibre/epoxy laminates by exploiting synergy between graphene and silver nano-inclusions. Composites Part A: Applied Science and Manufacturing, 69, 72-82 (2015).

https://doi.org/10.1016/j.compositesa.2014.10.024

[35] Wu D., Gao X., Sun J., Wu D., Liu Y., Kormakov S., Zheng X., Huang Y., Guo Z.: Spatial confining forced network assembly for preparation of high-performance conductive polymeric composites. Composites Part A: Applied Science and Manufacturing, 102, 88-95 (2017). https://doi.org/10.1016/j.compositesa.2017.07.027 
[36] Gao X., Huang Y., Liu Y., Kormakov S., Zheng X., Wu D., Wu D.: Improved electrical conductivity of PDMS/ SCF composite sheets with bolting cloth prepared by a spatial confining forced network assembly method. RSC Advances, 7, 14761-14768 (2017). https://doi.org/10.1039/C7RA02061A

[37] Kormakov S., He X., Huang Y., Liu Y., Sun J., Zheng X., Skopincev I., Gao X., Wu D.: A mathematical model for predicting conductivity of polymer composites with a forced assembly network obtained by SCFNA method. Polymer Composites, in press (2018). https://doi.org/10.1002/pc.24942

[38] He X., Huang Y., Liu Y., Zheng X., Kormakov S., Sun J., Zhuang J., Gao X., Wu D.: Improved thermal conductivity of polydimethylsiloxane/short carbon fiber composites prepared by spatial confining forced network assembly. Journal of Materials Science, 53, 14299-14310 (2018).

https://doi.org/10.1007/s10853-018-2618-4
[39] Hussein A., Kim B.: Graphene/polymer nanocomposites: The active role of the matrix in stiffening mechanics. Composite Structures, 202, 170-181 (2018). https://doi.org/10.1016/j.compstruct.2018.01.023

[40] Guo M., Yi X., Liu G., Liu L.: Simultaneously increasing the electrical conductivity and fracture toughness of carbon-fiber composites by using silver nanowiresloaded interleaves. Composites Science and Technology, 97, 27-33 (2014). https://doi.org/10.1016/j.compscitech.2014.03.020

[41] Kim H. S., Hahn H. T.: Graphite fiber composites interlayered with single-walled carbon nanotubes. Journal of Composite Materials, 45, 1109-1120 (2011). https://doi.org/10.1177/0021998311402726 